\title{
Data processing in hospital bacteriology: experience of 18 months' trial
}

\author{
J. L. WHITBY ${ }^{1}$ AND JANET N. BLAIR
}

From the Department of Bacteriology, Queen Elizabeth Hospital, Birmingham

SYNOPSIS The nature of bacteriological investigations creates data processing problems. Nonnumerical results must be coded. This may be done retrospectively or at the bench, the former? method involving extra work and staff, the latter implying simple codes, stringent checking, a or nearby computer, and decoding programs. The use of a shared computer for producing daily reports diminishes departmental autonomy. Benefits occur in more readily available records and statistics, $\mathscr{C}$ quality control, epidemiology, and diagnostic bacteriology.

For the past 18 months all routine work handled by the Bacteriology Department of the Queen Elizabeth Hospital, Birmingham, has been recorded in computer-readable form. The following account outlines and discusses the experience gained, problems which have been encountered, and some benefits which have accrued.

\section{Brief Outline of the System}

At the time of admission of the patient (there is no Outpatient Department at the Hospital) the Registration Department pre-punches 1080 column IBM cards which are preprinted to serve as pathology request cards. Standard patient identification details are punched into columns 3 to 28 . The cards accompany patients to the wards, and clinical and other details are entered by hand at the time of use. One card accompanies each specimen to the laboratory. Here, by means of an IBM 836 punch machine, identification details are duplicated from the request card on to appropriate preprinted laboratory work cards. Different but superimposable designs are used for urine, faeces, sputum, swabs, and cerebrospinal fluid. Details of the style of cards have been published elsewhere (Whitby and Blair, 1970). The date and laboratory number are punched manually, and simultaneously a day book list is compiled by the electrically linked typewriter. As work proceeds, the cards are completed in code by the technicians. Should culture produce significant growth another and different card is used to enter diagnostic tests

'Present address: Department of Bacteriology and Immunology, University of Western Ontario, Canada.

Received for publication 30 September 1971. and antibiotic sensitivities for each organism isolated. These coded results are transferred to $\vec{\varphi}$ punch cards which are fed into an IBM 1440 com- N puter together with validating, decoding, and $\square$ printing programs. The cards are previously checked visually for errors of sense and of transcription. This method is used in preference to validation punching. Visual checking detects error in approximately $2.5 \%$ of the completed cards. After correction the validation program subsequently rejects approximately $0.4 \%$ of the reports because of mispunches. Amongst the visually detected errors some would have been detected by the program but others would not. Traditionally worded reports and a computerreadable form of these are in this way produced in $:$ one operation.

\section{Problem Areas}

When the specimen arrives in the laboratory it is generally not known whether it will require few or o many procedures to produce a definitive result. The results themselves are a mixture of numerical data $\odot$ and non-numerical findings which are potentially $N$ very variable. The conversion of non-numerical $\underset{\mathrm{W}}{\mathrm{N}}$ results into a computer-readable form requires the ${ }_{\sigma}^{\omega}$ use of codes. Coding may be done retrospectively after reporting, or at the laboratory bench as work $\frac{0}{\Phi}$ proceeds.

Retrospective systems include those described by Cheatle (1964), Schneierson and Amsterdam (1967), Stirland, Hillier and Steyger (1969), and Alexander, $\mathbb{\otimes}$ Connigale, Johnson, Poulter, and Wakefield (1970). $\frac{\text { त }}{\mathbb{D}}$ At the bench it may be achieved by using a wide selection (244) of prepunched cards (Lindberg, 1965, 
1968), preprinted work sheets with multiple choice questions (Gabrieli, Pessin, Thorpe, and Palmer, 1967), preprinted and prepunched description cards (Straumfjord, Spraberry, Biggs, and Noto, 1967), or cards punched with patient identification and containing numbered labelled spaces for the entry of coded results (Whitby and Blair, 1970). Pribor and Welkowitz (1968) also report experience of bench coding without stating the choice of method.

The choice of codes is important. If punch cards are used there are severe limitations of space. If codes are not to be cumbersome in use they must be simple. The computer itself may also limit the type of coding that may be acceptable. Methods of coding and some of the problems involved have been mentioned elsewhere (College of American Pathologists, 1965; Association of Clinical Pathologists Working Party, 1968; Stirland et al, 1969; Whitby and Blair, 1970).

In practice our codes have proved acceptable and simple for technicians' use at the bench. The need for simplicity in the use of codes was considered more important than economy in the use of cards and the modifications during two years' use have been concerned with further simplification. Providing the facility for possible expansion is considered when compiling codes, no great problem is encountered in modifying the program. Instead of attempting to provide a coding for every contingency, provision was made for a handwritten comment to be added to the printed report where necessary. Approximately $5 \%$ of reports require such additions.

A criticism of this method is the amount of key punching of data that it involves (Whitby and Lutz, 1971). However, with such potentially variable results the use of prepunched cards involves a formidable number (Lindberg, 1968). Mark sensing eliminates the process of transcription but was rejected as unpractical in a bacteriological laboratory. Mark-sensed cards impose an even more rigid framework than coded entries, and the device of using an unmarked area to generate a result, while doubling the capacity of the card, was felt to be undesirable. Furthermore, the cards may be contaminated in the work area, rendering them electrically or optically unreadable and possible sources of infection. With on-line installations there is the possibility of using VDUs at the bench as a means of data input. At the present time the cost of a sufficient number would be very high.

The available computer is an IBM $144016 \mathrm{~K}$ model housed some 200 yards away from the department and used regularly by members of the Birmingham University Medical School, several departments of the Queen Elizabeth Hospital, and periodically by departments of other hospitals in the
United Birmingham Hospitals group. The use of a shared second generation computer for producing daily reports imposes inevitable constraints on departmental autonomy. Computer time is available at a set time each day. Routinely a 15 -minute period between $1.00 \mathrm{pm}$ and $2.00 \mathrm{pm}$ has proved satisfactory but Saturdays and bank holidays initially posed problems.

It is necessary to retain a method of producing at least the more urgent reports in the event of a breakdown. Total breakdown has occurred twice during the 18-month period. There have been more frequent short delays due to defects in peripherals, particularly the line printer. The IBM punch machine has been generally reliable but even a minor defect can cause delay and frustration.

The use of a punch machine instead of a typewriter or conventional two-part paper for producing reports implies the availability of a skilled punch operator. It is necessary to have adequate cover for absences, and while we have so far had no staffing problems this might be an area of difficulty as there is competition from industry for such personnel.

Programs other than those producing the daily reports are generally run in the afternoon or evening. Because of the limited size of the computer it was necessary to have separate validation and decoding and printing programs and to write them in machine code. Fortran IV was used for all other programs.

\section{Potential Benefits}

The potential benefits from an efficient data handling system may conveniently be considered under laboratory routine, work load, quality control, epidemiology and control of infection, and diagnostic bacteriology.

\section{LABORATORY ROUTINE}

The use of punched request cards produces a day book list automatically during the generation of work cards. When the number of reports is greater than 100 per day it is significantly quicker to produce punched cards instead of typewritten reports. One negative report can be typed in approximately 30 seconds and a positive one in approximately two minutes. Twenty negative reports can be sorted and punched in approximately five minutes and 20 positive reports can be sorted and punched in approximately 11 minutes.

After validating, and decoding, and printing the reports, the computer also prints a list of reports sent out that day. This is particularly useful in dealing with telephone enquiries. Each month the computer produces an alphabetically arranged record of all reports. One sheet (measuring $48 \mathrm{~cm} \times$ 


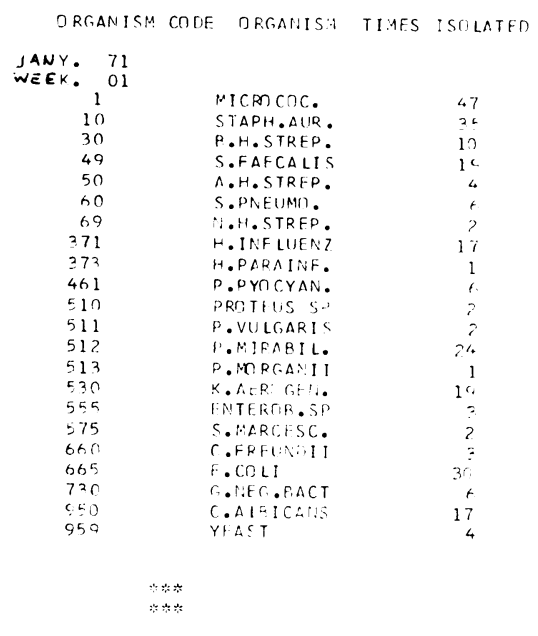

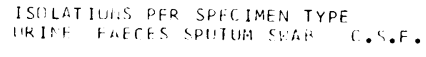

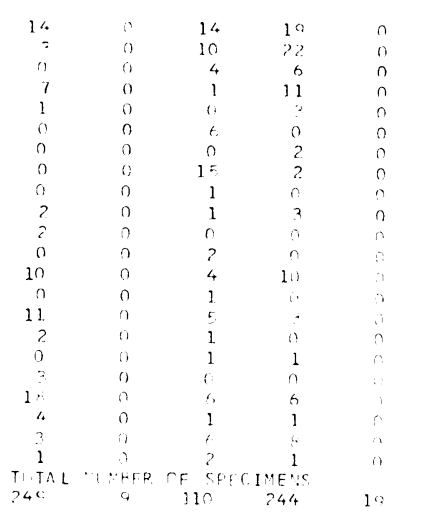

Fig. 1 An example of the list of isolations printed each week
$38 \mathrm{~cm}$ ) contains an average of 38 reports. The fact that the results are in code has not, in practice, detracted from the convenience of using this record when searching for old reports. The laboratory cards are filed in the usual way during the current month.

\section{WORK LOAD}

The sources of laboratory work can readily be analysed in terms of ward, type of specimen, proportion yielding significant growth, and permutations of these.

\section{QUALITY CONTROL}

The laboratory handles some 600 specimens per week and while files of work performed could conceivably be kept manually, the computer enables a number of situations to be rapidly examined and interpreted.

A weekly list of all bacterial species isolated, their respective frequency and their origin in terms of specimen type, shows up any unusual prevalence of a particular organism. This may be a laboratory contaminant, or misidentification, or it may be due to local cross infection or more widespread infection. Conversely abnormally low occurrences may be real or may be an indication of the less than optimum state of the culture medium used, or technical error.

This program has been run each week for a period of one year. It is run on Monday so that the printout of the previous week's work is available for laboratory staff on Monday afternoon or Tuesday morning, when any observation made is still relevant.

For example, Haemophilus influenzae is an organism which can fail to be recognized in labora- tory working and where failure of isolation may be due to unsuitability of the culture medium or inexperience of staff. The graph plots the weekly percentage of isolations of $\boldsymbol{H}$. influenzae from sputum specimens submitted (Fig. 2 and Table).

The fact that there is a computer-readable record of both biochemical data and antibiotic sensitivities of all bacterial species isolated enables a continuous check to be kept on bacterial populations and laboratory performance.

When, for example, the figures for sulphonamide sensitivity of Escherichia coli isolated from urine specimens are plotted cumulatively, the resulting graph is produced (Fig. 3).

The binomial distribution may be used as an indicator of the acceptability, or otherwise, of the percentage of Escherichia coli isolations recorded sensitive to sulphonamide each week.

A similar cumulative plotting for ampicillin sensitivity of Klebsiella sp. shows how changes in laboratory performance and/or bacterial population, which might otherwise escape detection, may be noticed (Fig. 4).

\section{EPIDEMIOLOGY}

Cumulative ward reports present all positive reports in a summarized form each month. Patterns for 0 individual wards are quite characteristic. These $\varphi$

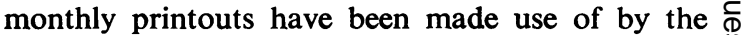
staff of the urological wards and renal unit but not $\stackrel{\mathcal{P}}{+}$ by clinicians in other parts of the hospital. A peri- $T$ odical information sheet referring to points of epidemiological significance might prove more acceptable.

During the winter of 1970 an unexpectedly large number of isolations of Serratia marcescens was noticed (Black and Hodgson, 1971). A retrospective 


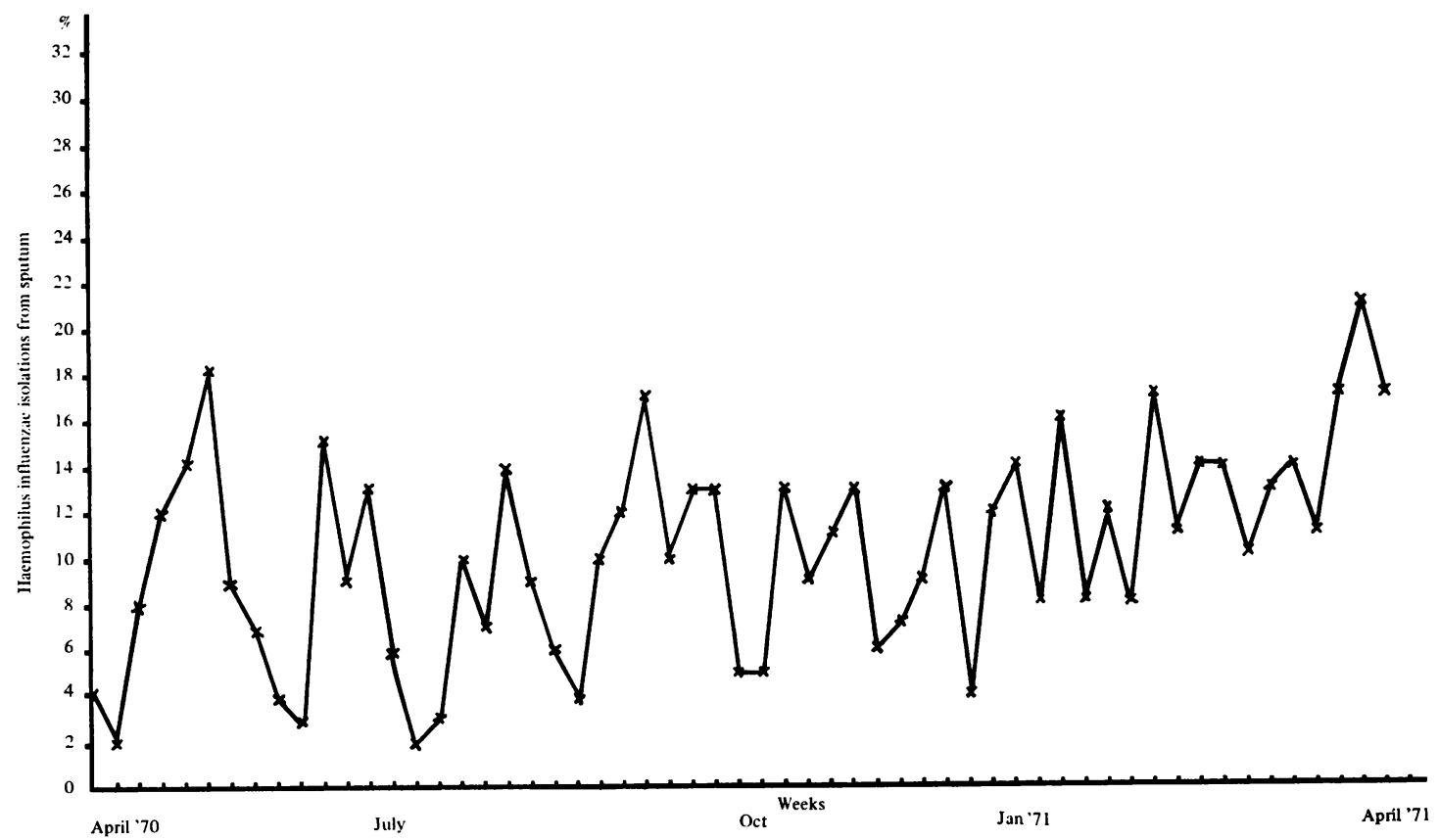

Fig. 2 Number of isolations of Haemophilus influenzae expressed as percentage of total sputum specimens, plotted weekly.

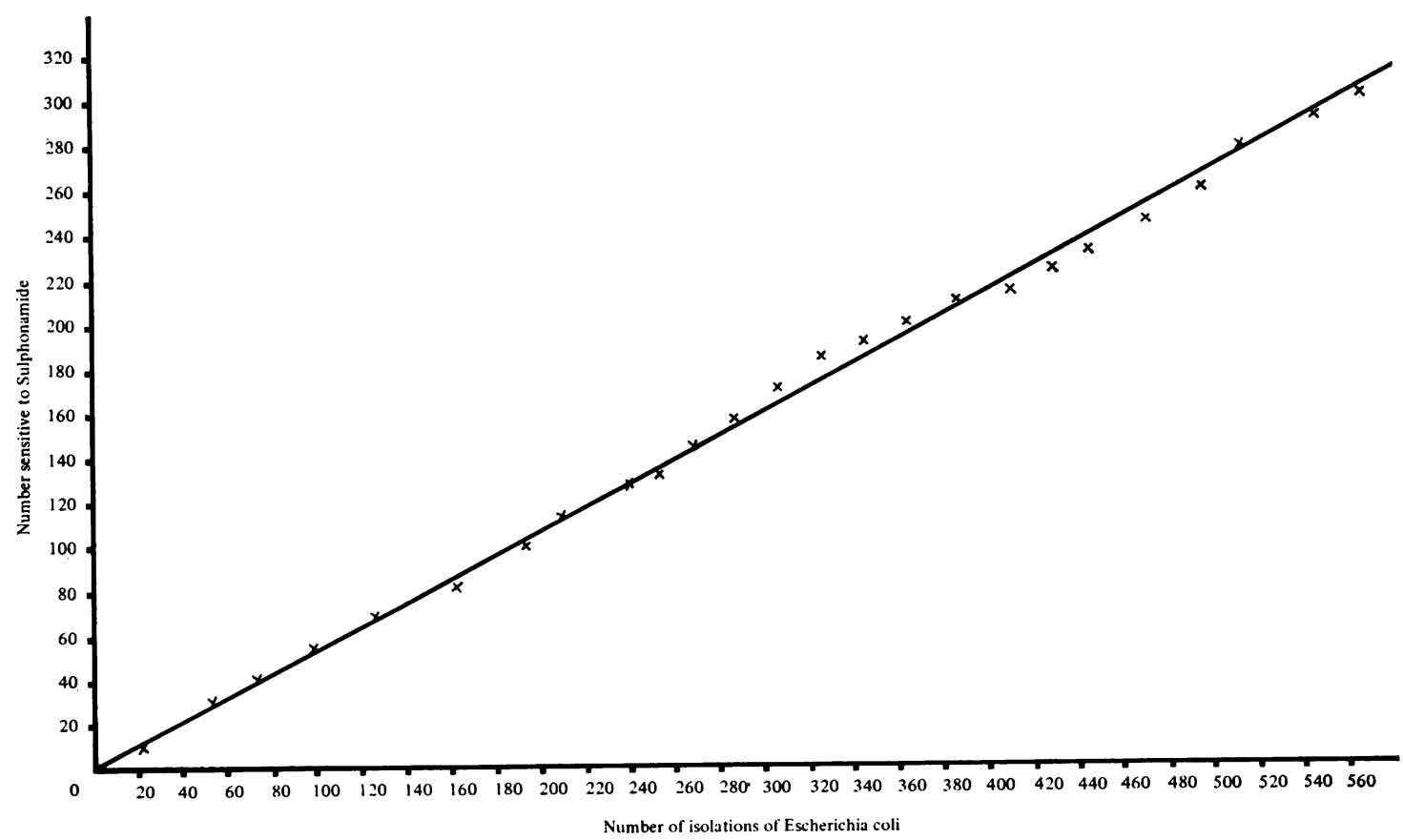

Fig. 3 Cumulative plotting of the number of isolations of Escherichia coli from urine recorded sensitive to sulphonamide against the total weekly number of isolations of Escherichia coli from urine. 
scan for all records of $S$. marcescens during the eight month period May-December produced the following figures (see Table).

A monthly printout of all isolations of multipleresistant Staphylococcus aureus strains and their source has proved another useful summary (Ridley, Barrie, Lynn, and Stead, 1970).

\section{DIAGNOSTIC BACTERIOLOGY}

The diagnostic tests recorded are currently not incorporated into the validation program because of the small size of the computer available. However, base lines are being established for this purpose and for monitoring the prevalence of local strains of, for example, the commoner Enterobacteriaceae.

\section{Conclusion}

Once the results of routine work have been converted into a computer-readable form, with no more effort at the bench, appreciably more information is available. This need no longer be only one-patient orientated but can be used within the laboratory for quality control, to monitor changes in antibiotic sensitivities, and for epidemiological purposes. With more sophisticated computers available and a net- work of terminals a central diagnostic service could be envisaged to help with the identification of unusual species (Lapage, Bascomb, Willcox, and Curtis, 1970; Lapage, 1971).

\begin{tabular}{llll}
\hline Ward No. of & Source & No. of Sex & Sex Ratio of \\
Different & All Admis- \\
& Patients & sions to In- \\
& & tensive \\
& & Therapy \\
& & Unit during \\
& & 1970
\end{tabular}

\begin{tabular}{|c|c|c|c|c|}
\hline $\begin{array}{l}1 \\
2\end{array}$ & $\begin{array}{l}1 \\
2\end{array}$ & $\begin{array}{l}\text { Sputum } \\
\text { Sputum/ } \\
\text { Wound swab1 }\end{array}$ & $\begin{array}{l}1 \\
2\left(1^{1}\right)\end{array}$ & $\begin{array}{l}\mathbf{F} \\
\mathbf{M}\end{array}$ \\
\hline 3 & 1 & Wound swab & 1 & M \\
\hline 4 & 1 & Urine & 1 & $\mathbf{F}$ \\
\hline 5 & 1 & Urine & 1 & $\mathbf{M}$ \\
\hline 6 & 3 & Wound swab 3 & 2 & $\mathrm{M}, 1 \mathrm{~F} \quad 1.4: 1$ \\
\hline $7+$ ITU & 24 & $\begin{array}{l}\text { Sputum } 14 \\
\text { Mouth swab 1 } \\
\text { Tracheostomy } 2 \\
\text { Wound swab 3 } \\
\text { Blood 3 } \\
\text { Urine 1 }\end{array}$ & $\begin{array}{l}11 \\
2\end{array}$ & 10M, 1F \\
\hline 8 & 2 & Tracheostomy 2 & $21^{2}$ & $\mathbf{F}$ \\
\hline $\begin{array}{l}9 \\
\text { Total }\end{array}$ & $\begin{array}{r}1 \\
36\end{array}$ & Urine & 1 & $\mathbf{F}$ \\
\hline
\end{tabular}

Table Isolations of Serratia marcescens during eightmonth period

${ }^{1}$ Patient previously spent some time in the intensive therapy unit. 
We gratefully acknowledge the extensive assistance of the computer unit of Birmingham University Medical School and Queen Elizabeth Hospital, and of $\mathrm{Mr} \mathrm{V}$. Trend, chief technician.

We wish to thank the Department of Health and Social Security for a grant in support of this trial.

\section{References}

Alexander, M. K., Connigale, J., Johnson, T., Poulter, I. R., and Wakefield, H. (1970). A data processing system for a hospital laboratory.J. clin. Path., 23, 77-80.

Association of Clinical Pathologists Working Party (1968). Data processing in clinical pathology. J. clin. Path., 21, 231-301.

Black, W. A., and Hodgson, R. (1971). Search for Serratia. J. clin. Path., 24, 444-448.

Cheatle, E. L. (1964). Automatic data processing in hospitals. Hospitals, 38,91-94.

College of American Pathologists (1965). Systematised Nomenclature of Pathology. (Committee on Nomenclature and Classification of Disease.) American Cancer Society and American Medical Association, Chicago.

Gabrieli, E. R., Pessin, V., Thorpe, J., and Palmer, R. C. C. (1967). Initial experience with and potential of data processing and computer technics in a hospital clinical laboratory. Amer. $J$. clin. Path., 47, 60-68.

Lapage, S. P., Bascomb, S., Willcox, W. R., and Curtis, M. A. (1970). Computer identification of bacteria. In Automation, Mechani- sation, and Data Handling in Microbiology, edited by A. Baillie and R. J. Gilbert (Society for Applied Bacteriology Technical Series No. 4), pp. 1-22. Academic Press, London and New York.

Lapage, S. P. (1971). Thoughts on screening tests in bacteriology. J. clin. Path., 24, 404-408.

Lindberg, D. A. B. (1965). Electronic reporting, processing and retrieval of clinical laboratory data. Bact. Rev., 29, 554-559.

Lindberg, D. A. B. (1968). The Computer and Medical Care. Thomas, Springfield, lllinois.

Pribor, H. C., and Welkowitz, W. (1968). Application of computers in a hospital clinical laboratory. J. med. Soc. N. J., 65, 249-253.

Ridley, M., Barrie, D., Lynn, R., and Stead, K. C. (1970). Antibiotic resistant Staphylococcus aureus and hospital antibiotic policies. Lancet, 1, 230-233.

Schneierson, S. S., and Amsterdam, D. (1967). A manual punch card system for recording, filing, and analyzing antibiotic sensitivity test results. Amer. J. clin. Path., 47, 818-820.

Stirland, R. M., Hillier, V. F., and Steyger, M. G. (1969). Analysis of hospital bacteriological data. J. clin. Path., 22, Suppl. (Coll. Path.), 3, 82-86.

Straumf jord, J. V., Jr., Spraberry, M. N., Biggs, H. G., and Noto, T. A. (1967). Electronic data processing system for clinical laboratories. Amer. J. clin. Path., 47, 661-676.

Whitby, J. L., and Blair, J. N. (1970). A computer-linked data processing system for routine hospital bacteriology. In Automation, Mechanisation and Data Handling in Microbiology, edited by A. Baillie and R. J. Gilbert (Society for Applied Bacteriology Technical Series No. 4), pp. 23-32. Academic Press, London and New York.

Whitby, L. G., Lutz, W. (1971). Principles and Practice of Medical Computing. Churchill Livingstone, Edinburgh and London. 